\title{
EVALUASI EFEKTIVITAS PEMELIHARAAN MENGGUNAKAN ALAT REMINDER PEMELIHARAAN DENGAN PENERAPAN TOTAL PRODUCTIVE MAINTENANCE DI PT. PLN (PERSERO) RAYON HARUKU
}

\author{
J. M. Tupan \\ Program Studi Teknik Industri, Fakultas Teknik Universitas Pattimura, Ambon \\ A Simanjuntak \\ Program Studi Teknik Mesin, Fakultas Teknik Universitas Pattimura, Ambon \\ Luthfy Aditiar \\ PLN Wilayah Maluku dan Maluku Utara, Ambon
}

\begin{abstract}
ABSTRAK
Pemeliharaan terencana diSatuan Pembangkit Diesel (SPD )harus dilakukan tepat waktu yang dapat mendeteksi atau mengetahui masalah lebih dini.Pada kondisi riil dilapangan, kegiatan pemeliharaan di PLTD Rayon Haruku kurang termonitor. PLTD ini memerlukans uatu metode yang mampu mengatasi permasalahan tersebut dengan jelas agar dapat melakukan peningkatan kinerja peralatan dan perawatan dengan optimal. Dengan alat reminder pemeliharaan, diharapkan dapat menjaga kondisi mesin agar selalu handal dan siap beroperasi serta tidak mengalami kerusakan pada waktu yang singkat, sehingga hasilnya dapat meningkatkan efektivitas pemeliharaan serta menekan nilai kerugian yang diakibatkan oleh kerusakan komponen mesin. Dari hasil penelitian ini didapat nilai Overall Equipment Effectiveness sebesar $94.37 \%$ yang menunjukkan bahwa proses penggunaan alat reminder pemeliharaan sangat membantu proses penerapan TPM secara ideal.
\end{abstract}

Kata Kunci:Pemeliharaan, AlatReminder Pemeliharaan, Total Productive Maintenance

\begin{abstract}
Planned maintenance at the Diesel Generating Unit (SPD) must be carried out on time that can detect or find out problems early. In the real conditions, maintenance activities in the PLTD Rayon Haruku are not monitored. This PLTD requires a method that can overcome these problems clearly to improve the performance of equipment and maintenance optimally. The maintenance reminder tool is expected to maintain the condition of the machine to always be operated and reliable and not suffer for damage in a short time. Then, the results can increase the effectiveness of maintenance and reduce the value of losses caused by damage to engine components. The results of this study show that the Overall Equipment Effectiveness value is $94.37 \%$ which means that the process of using maintenance reminder tools greatly helped the process of applying TPM ideally
\end{abstract}

Keywords: Maintenance, Maintenance Reminder Tools, Total Productive Maintenance

\section{PENDAHULUAN}

Pemeliharaan adalah tindakan merawat mesin atau peralatan pabrik dengan memperbaharui umur masa pakai dan kegagalan/kerusakan mesin. (Setiawan F.D, 2008). Kegiatan pemeliharaan sangat penting karena dapat memperpanjang kegunaan atau umur asset, menjamin ketersediaan optimum peralatan yang dipasang untuk produksi dan mendapatkan laba investasi maksimum yang mungkin, menjamin kesiapan operasional dari seluruh peralatan yang diperlukan dalam keadaan darurat setiap waktu, dan juga dapat menjamin keselamatan orang yang menggunakan sarana tersebut.

Pada Pembangkit Listrik Tenaga Diesel (PLTD), terdapat dua jenis pemeliharaan yaitu pemeliharaan terencana dan tidak terencana. Pemeliharaan terencana dilakukan berdasarkan waktu yaitu pemeliharaan rutin (P0-P5) dan pemeliharaan periodik (P6-P8), sedangkan pemeliharaan tidak terencana adalah pemeliharaan yang dilakukan karena terjadi gangguan kerusakan yang tidak terduga, sehingga harus dilakukan perbaikan secepatnya (bersifat darurat).

Pemeliharaan terencana pada Satuan Pembangkit Diesel (SPD) harus dilakukan tepat waktu, hal ini dikarenakan terdapat part-part yang mempunyai umur pakai sehingga harus diganti, dan apabila tidak diganti akan dapat mempengaruhi sistem dari mesin itu sendiri yang dapat berakibat lebih fatal. Pemeliharaan tepat waktu juga dapat mendeteksi atau mengetahui masalah lebih dini. Pemeliharaan juga tidak boleh dilakukan terlalu cepat ataupun terlalu lambat. 
Rendahnya tingkat produksi mesin menimbulkan kerugian yang besar bagi perusahaan diakibatkan oleh tidak teraturnya kegiatan pemeliharaan, terdapat dalam enam faktor yang disebut enam kerugian besar (six big losses). Adapun enam kerugian tersebut adalah downtime yang terdiri dari breakdown (kerusakan mesin/peralatan), set up and adjustment (kesalahan pemasangan dan penyetelan). Speed losses terdiri dari idling and minor stoppage losses disebabkan oleh kejadian - kejadian seperti pemberhentian mesin sejenak untuk pemeriksaan, kemacetan mesin dan reduced speed loss yaitu kerugian karena mesin tidak berkerja optimal (penurunan daya mampu operasi) terjadi ketika daya aktual mesin beroperasi lebih kecil dari daya mampu normal. Defect losses, terdiri dari process defect yaitu kerugian yang disebabkan karena adanya produk cacat maupun karena kerja produk diproses ulang dan reduced yield losses disebabkan material tidak terpakai atau sampah baku.

PLTD Rayon Haruku saat ini memiliki daya mampu $1.000 \mathrm{KW}$ dengan beban puncak rata-rata tahun 2016 sebesar $950 \mathrm{~kW}$, dengan cadangan daya yang sangat sedikit, tentunya tidak boleh ada mesin yang out akibat gangguan, karena akan terjadi defisit yang mengganggu kontinuitas pasokan listrik ke pelanggan.

Pada saat ini, kegiatan pemeliharaan di PLTD Rayon Haruku kurang termonitor, karena PLTD ini merupakan unit yang kecil dengan jumlah pegawai minim, dan belum adanya alur kerja yang terorganisir, sehingga kegiatan pemeliharaan sering terbengkalai atau tidak tepat waktu. Hal ini dapat dilihat dari frekuensi gangguan yang terjadi pada mesin akibat terlambatnya kegiatan pemeliharaan yang menyebabkan proses produksi listrik menjadi terhenti. Setelah adanya alat reminder pemeliharaan, diharapkan mampu membantu terciptanya pemeliharaan tepat waktu yang efektif pada mesin.

Oleh karena itu, diperlukan langkah - langkah yang efektif dan efisien dalam kegiatan pemeliharaan untuk dapat mencegah terjadinya masalah tersebut. Penelitian ini dilakukan untuk mendapatkan gambaran tentang kesesuaian faktor - faktor yang menentukan kebutuhan penerapan TPM (Total Productive Maintenance) dengan kondisi perusahaan dan melihat faktor mana dari six big losses tersebut yang dominan mempengaruhi terjadinya penurunan efektivitas mesin. Dengan demikian penulisan ini akan memberikan evaluasi perbaikan efektivitas mesin melalui penerapan TPM.

\section{LANDASAN TEORI}

\section{Pemeliharaan (Maintanance)}

Pemeliharaan adalah kegiatan untuk memelihara atau menjaga fasilitas/peralatan pabrik dan mengadakan perbaikan atau penyesuaian/penggantian yang diperlukan agar supaya terdapat suatu keadaan operasi produksi yang memuaskan sesuai dengan apa yang direncanakan (Sofyan Assauri, 2004). Pada umumnya sebuah produk yang dihasilkan oleh manusia, tidak ada yang tidak mungkin rusak, tetapi usia penggunaannya dapat diperpanjang dengan melakukan perbaikan yang dikenal dengan pemeliharaan. (Corder, Antony, K. Hadi, 1992). Oleh karena itu, sangat dibutuhkan kegiatan pemeliharaan yang meliputi kegiatan pemeliharaan dan perawatan mesin yang digunakan dalam proses produksi. Dari beberapa pendapat di atas bahwa dapat disimpulkan bahwa kegiatan pemeliharaan dilakukan untuk merawat ataupun memperbaiki peralatan perusahaan agar dapat melaksanakan produksi dengan efektif dan efisien sesuai dengan pesanan yang telah direncanakan dengan hasil produk yang berkualitas.

Menurut Daryus A, (2008) dalam bukunya manajemen pemeliharaan mesin, Tujuan pemeliharaan yang utama dapat didefenisikan sebagai berikut:

1. Untuk memperpanjang asset

2. Untuk menjamin ketersediaan optimum peralatan yang dipasang untuk produksi dan mendapatkan laba investasi maksimum yang mungkin

3. Untuk menjamin kesiapan operasional dari seluruh peralatan yang diperlukan dalam keadaan darurat setiap waktu

4. Untuk menjamin keselamatan orang yang menggunakan sarana tersebut.

Sedangkan menurut Sofyan Assauri, tujuan pemeliharaan adalah:

1. Kemampuan produksi dapat memenuhi kebutuhan sesuai dengan rencana produksi

2. Menjaga kualitas pada tingkat yang tepat untuk memenuhi apa yang dibutuhkan oleh produk itu sendiri dan kegiatan produksi yang tidak terganggu

3. Untuk membantu mengurangi pemakaian dan penyimpangan yang di luar batas dan menjaga modal yang di investasikan tersebut

4. Untuk mencapai tingkat biaya pemeliharaan serendah mungkin, dengan melaksanakan kegiatan pemeliharaan secara efektif dan efisien

5. Menghindari kegiatan pemeliharaan yang dapat membahayakan keselamatan para pekerja 
6. Mengadakan suatu kerja sama yang erat dengan fungsi-fungsi utama lainnya dari suatu perusahaan dalam rangka untuk mencapai tujuan utama perusahaan yaitu tingkat keuntungan (return on investment) yang sebaik mungkin dan total biaya yang terendah

Menurut pendapat Agus Ahyari, (2002) fungsi pemeliharaan adalah agar dapat memperpanjang umur ekonomis dari mesin dan peralatan produksi yang ada serta mengusahakan agar mesin dan peralatan produksi tersebut selalu dalam keadaan optimal dan siap pakai untuk pelaksanaan proses produksi.

Keuntungan-keuntungan yang akan diperoleh dengan adanya pemeliharaan yang baik terhadap mesin, adalah sebagai berikut :

1. Mesin dan peralatan produksi yang ada dalam perusahaan yang bersangkutan akan dapat dipergunakan dalam jangka waktu panjang,

2. Pelaksanaan proses produksi dalam perusahaan yang bersangkutan berjalan dengan lancar,

3. Dapat menghindarkan diri atau dapat menekan sekecil mungkin terdapatnya kemungkinan kerusakan-kerusakan berat dari mesin dan peralatan produksi selama proses produksi berjalan,

4. Peralatan produksi yang digunakan dapat berjalan stabil dan baik, maka proses dan pengendalian kualitas proses harus dilaksanakan dengan baik pula

5. Dapat dihindarkannya kerusakan-kerusakan total dari mesin dan peralatan produksi yang digunakan,

6. Apabila mesin dan peralatan produksi berjalan dengan baik, maka penyerapan bahan baku dapat berjalan normal,

7. Dengan adanya kelancaran penggunaan mesin dan peralatan produksi dalam perusahaan, maka pembebanan mesin dan peralatan produksi yang ada semakin baik.

Secara umum, ditinjau dari saat pelaksanaan Pekerjaan pemeliharaan dikategorikan dalam dua cara (Corder, Antony, K. Hadi, 1992), yaitu :

1. Pemeliharaan terencana (planned maintenance)

2. Pemeliharaan tak terencana (unplanned maintenance)

\section{Total Productive Maintanance (TPM)}

Total Productive Maintenance (TPM) merupakan suatu sistem pemeliharaan dan perbaikan pada mesin atau peralatan yang melibatkan semua divisi dan karyawan mulai dari operator hingga manajemen puncak berdasarkan komitmen yang telah disepakati bersama. Konsep Total Productive Maintenance (TPM) pertama kali diterapkan di Jepang pada tahun 1971. Pada awalnya, Jepang belajar pemeliharaan produktifitas dari Amerika, lalu digabungkan dengan kebudayaan Jepang (kerja tim). TPM merupakan pencapaian efisiensi pemeliharaan mandiri melalui satu sistem yang lengkap berdasarkan keikut sertaan seluruh karyawan. Selain itu, TPM gabungan dari beberapa ilmu tingkah laku (manusia dan mesin), rekayasa sistem, ekologi (perubahan mesin), dan logistik.

TPM dirancang untuk mencegah terjadinya suatu kerugian karena terhentinya aktivitas produksi, yang disebabkan oleh kegagalan fungsi dari suatu peralatan (mesin), kerugian yang disebabkan oleh hilangnya kecepatan produksi mesin yang diakibatkan oleh kegagalan fungsi suatu komponen tertentu dari suatu mesin produksi, dan kerugian karena cacat yang disebabkan oleh kegagalan fungsi komponen atau mesin produksi. Jadi dapat di simpulkan secara sederhana bahwa tujuannya diaplikasikannya TPM adalah untuk mengoptimalkan efisiensi sistem produksi secara keseluruhan melalui aktivitas pemeliharaan dan perbaikan secara terorganisir.

Pada dasarnya, masalah pemeliharaan dan perbaikan sudah timbul sejak pemilihan instalasi atau peralatan. Hal ini disebabkan karena suatu sistem pemeliharaan dan perbaikan hanya dapat dilakukan dengan baik dan benar jika sekurang-kurangnya telah dipahami prinsip kerja dan karakteristik instalasi, konstruksi dan filsafat perancangannya, bahan dan energi yang digunakan, serta jumlah dan kualifikasi operator dan teknisi yang menanganinya. Dimana sistem pemeliharaan dan perbaikan meliputi semua usaha untuk menjamin agar instalasi senantiasa dapat berfungsi dengan baik, efisien dan ekonomis, sesuai dengan spesifikasi dan kemampuannya. Sementara disisi lain hal yang perlu diperhatikan bahwa biaya pemeliharaan dan perbaikan haruslah dapat ditekan seminimal mungkin.

Definisi lengkap TPM memuat 5 hal JIPM (Japan Institute of Plant Maintenance) 1971 antara lain:

1. Memaksimalkan efektifitas menyeluruh alat / mesin.

2. Menerapkan sistem preventive maintenance yang komprehensif sepanjang umur mesin / peralatan.

3. Melibatkan seluruh departemen perusahaan.

4. Melibatkan semua karyawan dari top management sampai karyawan lapangan.

5. Mengembangkan preventive maintenance melalui manajemen motivasi aktivitas kelompok kecil mandiri 
Manfaat dari studi aplikasi TPM secara sistematik dalam rencana kerja jangka panjang pada perusahaan khususnya menyangkut faktor-faktor berikut:

1. Peningkatan produktifitas dengan mengunakan prisip prinsip TPM akan memenimalkan keruguan kerugian pada perusahaan

2. Meningkatkan kualitas dengan TPM, meminimalkan kerusakan pada mesin/peralatan dan downtime mesin dengan metode terfokus

3. Waktu delivery ke konsumen dapat ditepati karena produksi yang tampa gangguan akan lebih mudah untuk di laksanakan

4. Biaya produksi rendah karena rugi dan pekerjaan yang tidak memberi nilai tambah dapat dikurangi

5. Kesehatan dan keselamatan lingkungan kerja baik

6. Meningkatkan motivasi kerja , karena hak dan tanggung jawab di delegasikan pada setiap orang.

\section{Overall Equipment Effectiveness (OEE)}

Overall Equipment Effectiveness (OEE) merupakan produk dari six big losses pada mesin/peralatan. Keenam faktor dalam six big losses dapat di kelompokkan menjadi tiga komponen utama dalam OEE untuk di gunakan dalam mengukur kinerja mesin/peralatan yaitu: downtimes losses, speed losses dan defect losses

$\mathrm{OEE}=$ Avaibility $\mathrm{x}$ Performance X Quality

OEE merupakan ukuran menyeluruh yang mengidentifikasikan tingkat produktivitas mesin/peralatan dan kinerjanya secara teori. Pengukuran ini sangat penting untuk mengetahui area mana yang perlu untuk ditingkatkan produktivitas ataupun efisiensi mesin/peralatan dan juga dapat menunjukkan area bottleneck yang terdapat pada lintasan poduksi. OEE juga merupakan alat ukur untuk mengevaluasi dan memperbaiki cara yang tepat untuk mejamin penigkatan produktivitas penggunaan mesin/peralatan. Formula matematis dari overall equipment effectiveness (OEE) dirumuskan sebagai berikut :

$\mathrm{OEE}=$ Availability $\mathrm{x}$ Performance efficiency $\mathrm{x}$ Rate of quality product $\mathrm{x} 100 \%$

\section{Six Big Loss}

Tujuan utama dari TPM dan Program OEE adalah mengurangi atau menghilangkan apa yang disebut Six Big Losses - penyebab umum dari ketidak efisienan dari manufacturing. Menggunakan mesin /peralatan seefisien mungkin artinya adalah memaksimalkan fungsi dari kinerja mesin/peralatan produksi dengan tepat guna dan berdaya guna. Untuk dapat meningkatkan produktifitas mesin/peralatan yang digunakan maka perlu dilakukan analisis produktivitas dan efesiensi mesin/peralatan pada six big losses, adapun ke enam kerugian besar (six big losses) tersebut adalah sebagai berikut:

1. Downtime (Penurunan Waktu)

2. Speed Losses (Penurunan Kecepatan)

3. Defects (Cacat)

\section{Diagram Sebab Akibat}

Diagram Cause and Effect atau Diagram Sebab Akibat adalah alat yang membantu mengidentifikasi, memilah, dan menampilkan berbagai penyebab yang mungkin dari suatu masalah atau karakteristik kualitas tertentu. Diagram ini menggambarkan hubungan antara masalah dengan semua faktor penyebab yang mempengaruhi masalah tersebut.

Diagram fishbone ini dapat digunakan ketika kita perlu:

1. Mengenali akar penyebab masalah atau sebab mendasar dari akibat, masalah, atau kondisi tertentu

2. Memilah dan menguraikan pengaruh timbal balik antara berbagai faktor yang mempengaruhi akibat atau proses tertentu

3. Menganalisa masalah yang ada sehingga tindakan yang tepat dapat diambil

Manfaat menggunakan diagram fishbone ini:

1. Membantu menentukan akar penyebab masalah dengan pendekatan yang terstruktur

2. Mendorong kelompok untuk berpartisipasi dan memanfaatkan pengetahuan kelompok tentang proses yang dianalisis

3. Menunjukkan penyebab yang mungkin dari variasi atau perbedaan yang terjadi dalam suatu proses 
4. Meningkatkan pengetahuan tentang proses yang dianalisis dengan membantu setiap orang untuk mempelajari lebih lanjut berbagai faktor kerja dan bagaimana faktor faktor tersebut saling berhubungan

5. Mengenali area dimana data seharusnya dikumpulkan untuk pengkajian lebih lanjut

\section{METODE PENELITIAN}

Variabel dan Definisi Operasional

Variabel keputusan dapat dinotasikan dengan lambang X. Yang termasuk dalam indikator variabel keputusan dalam penilitian adalah sebagai berikut :
a. Availability Ratio $\left(\mathrm{X}_{1}\right)$
b. Performance Efficiency $\left(\mathrm{X}_{2}\right)$
c. Rate Of Quality Product $\left(\mathrm{X}_{3}\right)$

Variabel keputusan merupakan suatu indikator untuk mencapai variabel tujuan. Yang mana variabel tujuan adalah Efektivitas Alat.

\section{Metode Analisa Data}

Data yang diperoleh dari proses pengumpulan data perusahaan selanjutnya akan dilakukan perhitungan dengan menggunakan metode Overall Equipment Effectiveness (OEE), Six Big Losses dan Fishbone Diagram.

Berikut ini merupakan flowchart dari penelitian ini.

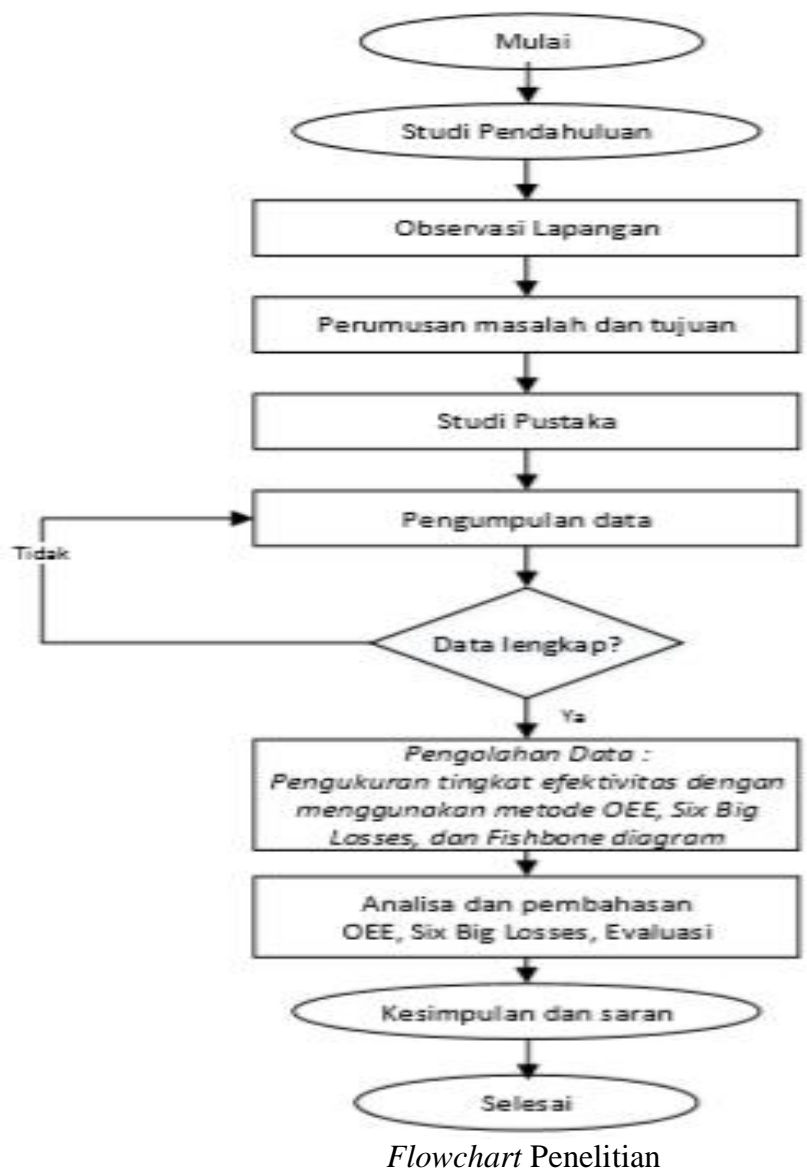

\section{HASIL DAN PEMBAHASAN}

Data KWH Produksi

PLTD Rayon Haruku sebagai pembangkit listrik tenaga diesel memproduksi listrik secara kontinyu dan memberikan suplai listrik untuk pelanggan PLN Rayon Haruku. Berikut ini merupakan rekapitulasi dari laporan kwh produksi mesin MTU 12V2000 G62 PLTD Rayon Haruku 
Data Kwh Produksi Januari - Desember 2016

\begin{tabular}{|c|c|}
\hline Bulan & $\begin{array}{c}\text { KWH Produksi } \\
\text { (KWH) }\end{array}$ \\
\hline Januari & 116,784 \\
\hline Februari & 100,056 \\
\hline Maret & 182,784 \\
\hline April & 179,160 \\
\hline Mel & 171,192 \\
\hline Juni & 176,400 \\
\hline Jull & 192,048 \\
\hline Agustus & 169,200 \\
\hline September & 186,240 \\
\hline Oktober & 193,344 \\
\hline sumber. laporan bulanan pembangkitan bulan Januari - Desember
\end{tabular}

*sumber. laporan bulanan pembangkitan bulan Januari - Desember 2016 PLTD Haruku

\section{Data Jam Kerja Dan Delay Mesin}

Dari hasil pengamatan pada mesin pembangkitan, delay mesin disebabkan karena faktor faktor berikut.

1. Tidak operasi karena adanya pemeliharaan terencana.

2. Tidak operasi karena gangguan, terjadi ketika mesin tiba - tiba harus dilakukan emergency off karena mesin mengalami kerusakan, sehingga dilakukan pemeliharaan secara mendadak untuk mengatasi kerusakan yang terjadi.

\begin{tabular}{|c|c|c|c|c|}
\hline Bulan & $\begin{array}{c}\text { Jam Kerja } \\
\text { Tersedia }\end{array}$ & $\begin{array}{c}\text { Tidak } \\
\text { Operasi } \\
\text { Terencana }\end{array}$ & $\begin{array}{c}\text { Tidak Operasi } \\
\text { Gangguan }\end{array}$ & $\begin{array}{c}\text { Total } \\
\text { Delay }\end{array}$ \\
\hline Januari & 720 & 17 & 1 & 18 \\
\hline Februari & 696 & 12 & 2 & 14 \\
\hline Maret & 744 & 10 & 0 & 10 \\
\hline April & 720 & 12 & 0 & 12 \\
\hline Mei & 744 & 16 & 2 & 18 \\
\hline Juni & 720 & 17 & 3 & 20 \\
\hline Jull & 744 & 12 & 0 & 12 \\
\hline Agustus & 744 & 11 & 1 & 12 \\
\hline September & 720 & 12 & 0 & 12 \\
\hline Oktober & 744 & 16 & 2 & 18 \\
\hline November & 720 & 11 & 4 & 15 \\
\hline Desember & 744 & 16 & 2 & 18 \\
\hline
\end{tabular}

"sumber: laporan bulanan pembangkitan bulan Januari - Desember 2016 PLTD Haruku

\section{Penentuan Availability Ratio}

Availability merupakan rasio dari operation time, dengan mengeliminasi downtime peralatan, terhadap loading time. Rumus yang digunakan untuk mengukur availability ratio adalah:

$$
\text { Availability }=\frac{\text { operation } \text { Time }}{\text { Loading Time }} \times 100 \%
$$


Operation time dihitung dengan rumus:

\section{Operation time $=$ Loading Time - Sudden Down Time}

Loading time adalah waktu yang tersedia perbulan dikurangi dengan waktu, sedangkan downtime yang telah ditetapkan oleh perusahaan (planned downtime).

\section{Loading Time = Available Time -Planned Downtime}

Available time ( jam kerja tersedia ) adalah jumlah waktu yang tersedia dalam setiap bulannya yaitu:

24 Jam X Jumlah hari dalam sebulan

Total Loading Time (Dalam satuan jam)

\begin{tabular}{|c|c|c|c|}
\hline Bulan & $\begin{array}{l}\text { Available } \\
\text { Time }\end{array}$ & $\begin{array}{l}\text { Planned } \\
\text { Downtime }\end{array}$ & Loading Time \\
\hline Januart & 720 & 17 & 703 \\
\hline Februari & 696 & 12 & 684 \\
\hline Maret & 744 & 10 & 734 \\
\hline April & 720 & 12 & 708 \\
\hline Mel & 744 & 16 & 728 \\
\hline Juni & 720 & 17 & 703 \\
\hline Jull & 744 & 12 & 732 \\
\hline Agustus & 744 & 11 & 733 \\
\hline September & 720 & 12 & 708 \\
\hline Oktober & 744 & 16 & 728 \\
\hline November & 720 & 11 & 709 \\
\hline Desember & 744 & 16 & 728 \\
\hline
\end{tabular}

Total Downtime (Dalam satuan jam)

\begin{tabular}{|c|c|c|c|c|}
\hline Bulan & $\begin{array}{c}\text { Available } \\
\text { Time }\end{array}$ & $\begin{array}{c}\text { Planned } \\
\text { Downtime }\end{array}$ & $\begin{array}{c}\text { Sudden } \\
\text { Downtime }\end{array}$ & $\begin{array}{c}\text { Total } \\
\text { Downtime }\end{array}$ \\
\hline Januari & 720 & 17 & 1 & 18 \\
\hline Februari & 696 & 12 & 2 & 14 \\
\hline Maret & 744 & 10 & 0 & 10 \\
\hline April & 720 & 12 & 0 & 12 \\
\hline Mei & 744 & 16 & 2 & 18 \\
\hline Juni & 720 & 17 & 3 & 20 \\
\hline Jull & 744 & 12 & 0 & 12 \\
\hline Agustus & 744 & 11 & 1 & 12 \\
\hline September & 720 & 12 & 0 & 12 \\
\hline Oktober & 744 & 16 & 2 & 18 \\
\hline November & 720 & 11 & 4 & 15 \\
\hline Desember & 744 & 16 & 2 & 18 \\
\hline
\end{tabular}

Total Perhitungan Availability Ratio

\begin{tabular}{|c|c|c|c|}
\hline Bulan & $\begin{array}{c}\text { Loading } \\
\text { Time (jam) }\end{array}$ & $\begin{array}{c}\text { Operation } \\
\text { Time (Jam) }\end{array}$ & $\begin{array}{c}\text { Availability } \\
\text { Ratio }\end{array}$ \\
\hline Januari & 703 & 702 & $99.86 \%$ \\
\hline Februari & 684 & 682 & $99.71 \%$ \\
\hline Maret & 734 & 734 & $100.00 \%$ \\
\hline April & 708 & 708 & $100.00 \%$ \\
\hline Mel & 728 & 726 & $99.73 \%$ \\
\hline Juni & 703 & 700 & $99.57 \%$ \\
\hline Jull & 732 & 732 & $100.00 \%$ \\
\hline Agustus & 733 & 732 & $99.86 \%$ \\
\hline September & 708 & 708 & $100.00 \%$ \\
\hline Oktober & 728 & 726 & $99.73 \%$ \\
\hline November & 709 & 705 & $99.44 \%$ \\
\hline Desember & 728 & 726 & $99.73 \%$ \\
\hline
\end{tabular}

*hasil pengolahan data 


\section{Perhitungan Performance Efficiency}

Perhitungan performance efficiency dimulai dengan perhitungan ideal cycle time. Ideal cycle time merupakan waktu siklus ideal mesin setelah pemeliharaan agar dapat beroperasi kembali. Untuk menghitung ideal cycle time maka digunakan persamaan berikut:

$$
\begin{aligned}
\% \text { jam kerja } & =\left(1-\frac{\text { Total Delay }}{\text { Available Time }}\right) \times 100 \% \\
& =\left(1-\frac{18}{720}\right) \times 100 \% \\
& =97.50 \%
\end{aligned}
$$

Presentase Jam Kerja Efektif

\begin{tabular}{|c|c|c|c|}
\hline Bulan & $\begin{array}{c}\text { Available time } \\
\text { (jam) }\end{array}$ & $\begin{array}{c}\text { Total Delay } \\
\text { (Jam) }\end{array}$ & $\begin{array}{c}\% \text { Jam } \\
\text { kerja }\end{array}$ \\
\hline Januari & 720 & 18 & $97.50 \%$ \\
\hline Februari & 696 & 14 & $97.99 \%$ \\
\hline Maret & 744 & 10 & $98.66 \%$ \\
\hline April & 720 & 12 & $98.33 \%$ \\
\hline Mei & 744 & 18 & $97.58 \%$ \\
\hline Juni & 720 & 20 & $97.22 \%$ \\
\hline Jull & 744 & 12 & $98.39 \%$ \\
\hline Agustus & 744 & 12 & $98.39 \%$ \\
\hline September & 720 & 12 & $98.33 \%$ \\
\hline Oktober & 744 & 18 & $97.58 \%$ \\
\hline November & 720 & 15 & $97.92 \%$ \\
\hline Desember & 744 & 18 & $97.58 \%$ \\
\hline
\end{tabular}

*hasil pengolahan data

KWH Produksi \& Loading Time

\begin{tabular}{|c|c|c|}
\hline Bulan & $\begin{array}{c}\text { KWH Produksi } \\
\text { (KWH) }\end{array}$ & $\begin{array}{c}\text { Loading Time } \\
\text { (jam) }\end{array}$ \\
\hline Januari & 116,784 & 703 \\
\hline Februari & 100,056 & 684 \\
\hline Maret & 182,784 & 734 \\
\hline April & 179,160 & 708 \\
\hline Mel & 171,192 & 728 \\
\hline Juni & 176,400 & 703 \\
\hline Jull & 192,048 & 732 \\
\hline Agustus & 169,200 & 733 \\
\hline September & 186,240 & 708 \\
\hline Oktober & 193,344 & 728 \\
\hline November & 183,936 & 709 \\
\hline Desember & 196,032 & 728 \\
\hline
\end{tabular}

Persamaan Waktu Siklus:

$$
\text { Waktu siklus }=\frac{\text { Loading time }}{\text { Produksi } K w h}
$$


Waktu Siklus Ideal

\begin{tabular}{|c|c|c|}
\hline Bulan & $\begin{array}{c}\text { Loading Time } \\
(\mathbf{f a m})\end{array}$ & $\begin{array}{c}\text { Waktu Siklus } \\
\text { Ideal (fam/kwh) }\end{array}$ \\
\hline Januari & 703 & 0.005869 \\
\hline Februari & 684 & 0.006699 \\
\hline Maret & 734 & 0.003962 \\
\hline April & 708 & 0.003886 \\
\hline Mel & 728 & 0.004150 \\
\hline Juni & 703 & 0.003875 \\
\hline Juli & 732 & 0.003750 \\
\hline Agustus & 733 & 0.004262 \\
\hline September & 708 & 0.003738 \\
\hline Oktober & 728 & 0.003674 \\
\hline November & 709 & 0.003774 \\
\hline Desember & 728 & 0.003624 \\
\hline
\end{tabular}

*hasil pengolahan data

Total Perhitungan Performance Efficiency

\begin{tabular}{|c|c|c|c|c|c|c|}
\hline Bulan & $\begin{array}{c}\text { Produkst } \\
(\mathbf{k w h})\end{array}$ & $\begin{array}{c}\text { KwH PS } \\
(\mathbf{k w h})\end{array}$ & $\begin{array}{c}\text { Processed } \\
\text { Amount } \\
(\mathbf{k w h})\end{array}$ & $\begin{array}{c}\text { Waktu } \\
\text { Silklus Ideal }\end{array}$ & $\begin{array}{c}\text { Operation } \\
\text { TIme } \\
(\mathbf{l a m})\end{array}$ & $\begin{array}{c}\text { Performance } \\
\text { Effletency }\end{array}$ \\
\hline Januari & 116,784 & 0 & 116,784 & 0.005869 & 702 & $97.64 \%$ \\
\hline Februari & 100,056 & 0 & 100,056 & 0.006699 & 682 & $98.28 \%$ \\
\hline Maret & 182,784 & 0 & 182,784 & 0.003962 & 734 & $98.66 \%$ \\
\hline April & 179,160 & 0 & 179,160 & 0.003886 & 708 & $98.33 \%$ \\
\hline Mei & 171,192 & 0 & 171,192 & 0.004150 & 726 & $97.85 \%$ \\
\hline Juni & 176,400 & 0 & 176,400 & 0.003875 & 700 & $97.64 \%$ \\
\hline Juli & 192,048 & 0 & 192,048 & 0.003750 & 732 & $98.39 \%$ \\
\hline Agustus & 169,200 & 0 & 169,200 & 0.004262 & 732 & $98.52 \%$ \\
\hline September & 186,240 & 0 & 186,240 & 0.003738 & 708 & $98.33 \%$ \\
\hline Oktober & 193,344 & 0 & 193,344 & 0.003674 & 726 & $97.85 \%$ \\
\hline November & 183,936 & 0 & 183,936 & 0.003774 & 705 & $98.47 \%$ \\
\hline Desember & 196,032 & 0 & 196,032 & 0.003624 & 726 & $97.85 \%$ \\
\hline
\end{tabular}

*hasil pengolahan data

Perhitungan Rate Of Quality Product

Rate Quality of Product merupakan suatu ratio yang menggambarkan kemampuan mesin dalam menghasilkan listrik sesuai dengan standar mesin tersebut. Rumus yang digunakan untuk perhitungan ini adalah persamaan berikut:

$$
\text { Rate of Quality Product }=\frac{\text { Processed Amount }- \text { defect amount }}{\text { Processed Amaount }} \times 100 \%
$$

Defect amount adalah jumlah KWH yang gagal dibangkitkan oleh mesin dalam waktu tertentu

Defect Amount = Daya mampu $\times$ Total Delay

Defect Amount

\begin{tabular}{|c|c|c|c|c|}
\hline $\begin{array}{l}\text { Daya Mampu } \\
\text { Mesin }\end{array}$ & Bulan & $\begin{array}{l}\text { Total Delay } \\
\text { (Jam) }\end{array}$ & $\begin{array}{l}\text { Defect Amount } \\
\text { (KWH) }\end{array}$ & $\begin{array}{l}\text { Processed Amount } \\
\text { (KWH) }\end{array}$ \\
\hline \multirow{12}{*}{$400 \mathrm{KVA}$} & Jenuari & 18 & 7.200 & 115.784 \\
\hline & Februari & 14 & 5,600 & 100,056 \\
\hline & Mare: & 10 & 4,000 & 182,784 \\
\hline & Aprol & 12 & 4,800 & 179,160 \\
\hline & Mei & 18 & 7,200 & 171,192 \\
\hline & Iuni & 20 & 8,000 & 176,400 \\
\hline & Julı & 12 & 4,800 & 192,048 \\
\hline & Agustus & 12 & 4,800 & 169,200 \\
\hline & September & 12 & 4.800 & 186.240 \\
\hline & Oktober & 18 & 7,200 & 193,344 \\
\hline & November & 15 & 6,000 & 183,936 \\
\hline & Desember & 18 & 7.200 & 196.032 \\
\hline
\end{tabular}


Rate Of Quality Product

\begin{tabular}{|c|c|c|c|}
\hline Bulan & $\begin{array}{c}\text { Processed Amount } \\
\text { (kwh) }\end{array}$ & $\begin{array}{c}\text { Defect Amount } \\
\text { (kwh) }\end{array}$ & $\begin{array}{c}\text { Rate Of Quality } \\
\text { Product }\end{array}$ \\
\hline Januari & 116,784 & 7,200 & $93.83 \%$ \\
\hline Februari & 100,056 & 5,600 & $94.40 \%$ \\
\hline Maret & 182,784 & 4,000 & $97.81 \%$ \\
\hline April & 179,160 & 4,800 & $97.32 \%$ \\
\hline Mei & 171,192 & 7,200 & $95.79 \%$ \\
\hline Juni & 176,400 & 8,000 & $95.46 \%$ \\
\hline Jull & 192,048 & 4,800 & $97.50 \%$ \\
\hline Agustus & 169,200 & 4,800 & $97.16 \%$ \\
\hline September & 186,240 & 4,800 & $97.42 \%$ \\
\hline Oktober & 193,344 & 7,200 & $96.28 \%$ \\
\hline November & 183,936 & 6,000 & $96.74 \%$ \\
\hline Desember & 196,032 & 7,200 & $96.33 \%$ \\
\hline
\end{tabular}

\section{Perhitungan Overall Equipment Effectiveness (OEE)}

Untuk mengetahui besarnya efektivitas alat reminder pemeliharaan dalam proses kegiatan pembangkitan listrik maka dilakukan perkalian availability ratio, performance efficiency, dan rate of quality product dengan persamaan sebagai berikut:

$\mathrm{OEE}=$ Avaibility $(\%) \mathrm{X}$ Performance Effeciency $(\%) \mathrm{X}$ Rate Of Quality Product $(\%)$

Perhitungan OEE

\begin{tabular}{|c|c|c|c|c|}
\hline Bulan & Availability Ratio & $\begin{array}{c}\text { Performance } \\
\text { Efficiency }\end{array}$ & $\begin{array}{c}\text { Rate Of Ouality } \\
\text { Product }\end{array}$ & OEE \\
\hline Januari & $99.86 \%$ & $97.64 \%$ & $93.83 \%$ & $91.49 \%$ \\
\hline Februari & $99.71 \%$ & $98.28 \%$ & $94.40 \%$ & $92.50 \%$ \\
\hline Maret & $100.00 \%$ & $98.66 \%$ & $97.81 \%$ & $96.50 \%$ \\
\hline April & $100.00 \%$ & $98.33 \%$ & $97.32 \%$ & $95.70 \%$ \\
\hline Mei & $99.73 \%$ & $97.85 \%$ & $95.79 \%$ & $93.48 \%$ \\
\hline Juni & $99.57 \%$ & $97.64 \%$ & $95.46 \%$ & $92.81 \%$ \\
\hline Juli & $100.00 \%$ & $98.39 \%$ & $97.50 \%$ & $95.93 \%$ \\
\hline Agustus & $99.86 \%$ & $98.52 \%$ & $97.16 \%$ & $95.60 \%$ \\
\hline September & $100.00 \%$ & $98.33 \%$ & $97.42 \%$ & $95.80 \%$ \\
\hline Oktober & $99.73 \%$ & $97.85 \%$ & $96.28 \%$ & $93.95 \%$ \\
\hline November & $99.44 \%$ & $98.47 \%$ & $96.74 \%$ & $94.72 \%$ \\
\hline Desember & $99.73 \%$ & $97.85 \%$ & $96.33 \%$ & $94.00 \%$ \\
\hline
\end{tabular}

*hasil pengolahan data

Berdasarkan Vorne Industry sebuah perusahan yang bergerak di bidang pengembangan industri menyatakan bahwa nilai OEE Standar Dunia adalah sebesar $85 \%$ dengan perhitungan:

1. Availability $>90 \%$

2. Performance $>95 \%$

3. Quality $>99 \%$

Sehingga OEE adalah $0.90 \times 0.95 \times 0.99 \times 100 \%=85 \%$.

Hasil perhitungan OEE pembangkit setelah digunakan alat reminder pemeliharaan mulai bulan Januari - Desember 2016 dilakukan rata - rata maka didapatkan nilai sebesar 94.37\%. Hal ini menunjukkan bahwa penggunaan alat reminder pemeliharaan sangat efektif dalam membantu penerapan TPM yang ideal. Karena dengan terjaganya kondisi yang optimal pada mesin dengan pemeliharaan yang teratur, maka akan berpengaruh pula pada keandalan mesin. Hal ini juga mampu mengurangi biaya yang harus dikeluarkan oleh perusahaan untuk melakukan perbaikan karena semakin berkurangnya kerusakan yang terjadi pada mesin 
Perhitungan Six Big Loss

A. Downtime Losses

1. Equipment Failure

$$
\text { Equipment Failure Loss }=\frac{\text { Total Breakdown Time }}{\text { Loading Time }} \times 100 \%
$$

Total Equipment Failure Loss

\begin{tabular}{|c|c|c|c|}
\hline Bulan & $\begin{array}{c}\text { Breakdown Time } \\
\text { (Jam) }\end{array}$ & $\begin{array}{l}\text { Loading Time } \\
\text { (Jam) }\end{array}$ & $\begin{array}{c}\text { Equipment Failure } \\
\text { Loss }\end{array}$ \\
\hline Januari & 1 & 703 & $0.14 \%$ \\
\hline Februari & 2 & 684 & $0.29 \%$ \\
\hline Maret & 0 & 734 & $0.00 \%$ \\
\hline April & 0 & 708 & $0.00 \%$ \\
\hline Mel & 2 & 728 & $0.27 \%$ \\
\hline Juni & 3 & 703 & $0.43 \%$ \\
\hline Juli & 0 & 732 & $0.00 \%$ \\
\hline Agustus & 1 & 733 & $0.14 \%$ \\
\hline September & 0 & 708 & $0.00 \%$ \\
\hline Oktober & 2 & 728 & $0.27 \%$ \\
\hline November & 4 & 709 & $0.56 \%$ \\
\hline Desember & 2 & 728 & $0.27 \%$ \\
\hline
\end{tabular}

2. Set Up And Adjustment

$$
\text { Set up and adjustment loss }=\frac{\text { Total setup and ad justment time }}{\text { Loading } \text { Time }} \times 100 \%
$$

\section{Set Up Loss}

\begin{tabular}{|c|c|c|c|}
\hline Bulan & $\begin{array}{c}\text { Total setup and } \\
\text { adjustment } \\
\text { (Jam) }\end{array}$ & $\begin{array}{c}\text { Loading } \\
\text { Time } \\
\text { (jam) }\end{array}$ & $\begin{array}{c}\text { Setup } \\
\text { Loss }\end{array}$ \\
\hline Januari & 17 & 703 & $2.42 \%$ \\
\hline Februari & 12 & 684 & $1.75 \%$ \\
\hline Maret & 10 & 734 & $1.36 \%$ \\
\hline April & 12 & 708 & $1.69 \%$ \\
\hline Mel & 16 & 728 & $2.20 \%$ \\
\hline Juni & 17 & 703 & $2.42 \%$ \\
\hline Juli & 12 & 732 & $1.64 \%$ \\
\hline Agustus & 11 & 733 & $1.50 \%$ \\
\hline September & 12 & 708 & $1.69 \%$ \\
\hline Oktober & 16 & 728 & $2.20 \%$ \\
\hline November & 11 & 709 & $1.55 \%$ \\
\hline Desember & 16 & 728 & $2.20 \%$ \\
\hline *hasil pengolahan data & & \\
\hline
\end{tabular}

\section{B. Speed Losses}

\section{Idling And Minor Stoppages}

Merupakan kerugian karena mesin beroperasi tanpa beban maupun karena berhenti sesaat muncul jika faktor eksternal mengakibatkan mesin atau peralatan berhenti atau beroperasi tanpa menghasilkan produk. Untuk mengetahui presentase dari faktor idling and minor stoppages dalam mempengaruhi efektivitas mesin, maka digunakan persamaan berikut:

$$
\text { Idling and minor stoppages }=\frac{\text { Non productive time }}{\text { Loading } \text { Time }} \times 100 \%
$$

Non Productive Time

\begin{tabular}{|c|c|c|c|c|}
\hline $\begin{array}{c}\text { Perslapan start } \\
\text { (menit) }\end{array}$ & $\begin{array}{c}\text { Pemanasan } \\
\text { mesin (menit) }\end{array}$ & $\begin{array}{c}\text { Sinkron } \\
\text { (Menit) }\end{array}$ & $\begin{array}{c}\text { Shutdown } \\
\text { (menit) }\end{array}$ & $\begin{array}{c}\text { Total } \\
\text { (menit) }\end{array}$ \\
\hline 5 & 5 & 3 & 5 & 18 \\
\hline
\end{tabular}

*sumber: data operasi mesin 
Total Non Productive Time Per Bulan

\begin{tabular}{|c|c|}
\hline Bulan & $\begin{array}{c}\text { Non Productive time } \\
\text { (Jam) }\end{array}$ \\
\hline Januart & 9.30 \\
\hline Februari & 8.40 \\
\hline Maret & 9.30 \\
\hline April & 9.00 \\
\hline Mel & 9.30 \\
\hline Juni & 9.00 \\
\hline Juli & 9.30 \\
\hline Agustus & 9.30 \\
\hline September & 9.00 \\
\hline Oktober & 9.30 \\
\hline November & 9.00 \\
\hline Desember & 9.30 \\
\hline *hasil pengolahan data & \\
\hline
\end{tabular}

Idling And Minor Stoppages

\begin{tabular}{|c|c|c|c|}
\hline Bulan & $\begin{array}{c}\text { Nou- } \\
\text { productive } \\
\text { time (jam) }\end{array}$ & $\begin{array}{c}\text { Loading } \\
\text { Time (jam) }\end{array}$ & $\begin{array}{c}\text { Idling and } \\
\text { Minur } \\
\text { Stoppage }\end{array}$ \\
\hline Januari & 9.30 & 703 & $1.32 \%$ \\
\hline Februari & 8.40 & 584 & $1.23 \%$ \\
\hline Maret & 9.30 & 734 & $1.27 \%$ \\
\hline April & 9.00 & 708 & $1.27 \%$ \\
\hline Mel & 9.30 & 728 & $1.28 \%$ \\
\hline Juni & 9.00 & 703 & $1.28 \%$ \\
\hline Jull & 9.30 & 732 & $1.7 \%$ \\
\hline Agustus & 9.30 & 733 & $1.27 \%$ \\
\hline September & 9.00 & 708 & $1.27 \%$ \\
\hline Oktober & 9.30 & 728 & $1.28 \%$ \\
\hline November & 9.00 & 709 & $1.27 \%$ \\
\hline Desember & 9.30 & 728 & $1.28 \%$ \\
\hline
\end{tabular}

2. Reduce Speed Loss

Reduced speed loss merupakan menurunnya produksi listrik yang timbul karena jam operasi aktual lebih kecil dari jam operasi mesin yang telah direncanakan. Untuk mendapatkan presentase Reduced speed loss dihitung dengan menggunakan persamaan berikut:

$\frac{\text { Operation Time }-(\text { ideal Cycle } \times \text { Total product process })}{\text { Loading Time }} \times 100 \%$

Reduce Speed Loss

\begin{tabular}{|c|c|c|c|c|c|}
\hline Bulen & $\begin{array}{l}\text { Oprnutian } \\
\text { Time (jam) }\end{array}$ & $\begin{array}{l}\text { Withiu SIlulux } \\
\text { Ideal }\end{array}$ & $\begin{array}{l}\text { Produkst } \\
\text { (Awh) }\end{array}$ & $\begin{array}{c}\text { Lavdling } \\
\text { Time } \\
\text { (fam) }\end{array}$ & $\begin{array}{l}\text { Redurcid } \\
\text { Speed } \\
I_{\max }\end{array}$ \\
\hline Januart & 702 & 0.0015859 & 116,764 & Tus & $2.36 \%$ \\
\hline Februart & 682 & 0.006699 & 100,056 & $6 \mathrm{~B} 4$ & $1.72 \%$ \\
\hline Marct & 734 & 0.003952 & 182,784 & 734 & $1.34 \%$ \\
\hline Aprll & 708 & 0.003836 & 179.160 & 708 & $1.67 \%$ \\
\hline Met & 726 & 0.00415 & 171,192 & 778 & $214 \%$ \\
\hline Junat & 700 & $000 \div 875$ & 176,400 & 703 & $235 \%$ \\
\hline Jull & 732 & 0.00375 & 192,048 & 732 & $1.51 \%$ \\
\hline Agustus & 732 & $0.00<262$ & 169.200 & 733 & $1.48 \%$ \\
\hline September & 708 & 0.003738 & 186.240 & 708 & $1.57 \%$ \\
\hline Ohtulher & 726 & 0003674 & 193,344 & 728 & $2.14 \%$ \\
\hline Navemilor & 705 & 0003774 & 183,976 & $7 n 9$ & $1.52 \%$ \\
\hline Drsenuluer & 726 & 0073624 & 196,072 & 778 & $2.14 \%$ \\
\hline
\end{tabular}

C. Quality Losses

1. Defect Loss

Losses ini terjadi karena adanya kerusakan yang dikarenakan terlambatnya kegiaan pemeliharaan mesin sehingga mesin harus berhenti operasi untuk pemeliharaan. Perhitungan defect loss dilakukan dengan menggunakan rumus: 
Defect loss $=\frac{\text { ideal cycle } \times \text { rework }}{\text { Loading Time }} \times 100 \%$

Perhitungan Defect Loss

\begin{tabular}{|c|c|c|c|c|c|}
\hline Bulan & $\begin{array}{c}\text { Loading } \\
\text { Time (Jam) }\end{array}$ & $\begin{array}{c}\text { Waktu Siklus } \\
\text { Ideal }\end{array}$ & $\begin{array}{l}\text { Defect } \\
\text { (KWH) }\end{array}$ & $\begin{array}{l}\text { defect } \\
\text { Time } \\
\text { (Jam) }\end{array}$ & $\begin{array}{l}\text { defect } \\
\text { Loss }\end{array}$ \\
\hline Januari & 703 & 0.005869 & 7200 & 1 & $0.33 \%$ \\
\hline Februart & 684 & 0.006699 & 5600 & 2 & $0.39 \%$ \\
\hline Maret & 734 & 0.003962 & 4000 & 0 & $0.22 \%$ \\
\hline April & 708 & 0.003886 & 4800 & 0 & $0.22 \%$ \\
\hline Mel & 728 & 0.00415 & 7200 & 2 & $0.23 \%$ \\
\hline Juni & 703 & 0.003875 & 8000 & 3 & $0.22 \%$ \\
\hline Jull & 732 & 0.00375 & 4800 & 0 & $0.20 \%$ \\
\hline Agustus & 733 & 0.004262 & 4800 & 1 & $0.23 \%$ \\
\hline September & 708 & 0.003738 & 4800 & 0 & $0.21 \%$ \\
\hline Oktober & 728 & 0.003674 & 7200 & 2 & $0.20 \%$ \\
\hline November & 709 & 0.003774 & 6000 & 4 & $0.21 \%$ \\
\hline Desember & 728 & 0.003624 & 7200 & 2 & $0.20 \%$ \\
\hline
\end{tabular}

2. Yield/Scrap Loss

Kerugian karena mesin tidak beroperasi menyebabkan hilangnya produksi listrik yang harusnya dapat disalurkan ke masyarakat. Untuk mengetahui presentase faktor yield/scrap loss yang mempengaruhi efektivitas mesin, maka digunakan rumus:

$$
\text { Yield/scrap loss }=\frac{\text { ideal Cycle } \times \text { scrap }}{\text { Loading Time }} \times 100 \%
$$

Total Perhitungan Yied Loss

\begin{tabular}{|c|c|c|c|c|}
\hline Bulan & $\begin{array}{l}\text { Loading Time } \\
\text { (Jam) }\end{array}$ & $\begin{array}{c}\text { Waktu SIklus } \\
\text { Ideal }\end{array}$ & Scrap(KWH) & $\begin{array}{l}\text { Yleld } \\
\text { Loss }\end{array}$ \\
\hline Januari & 703 & 0.005869 & 400 & $0.33 \%$ \\
\hline Februari & 684 & 0.006699 & 800 & $0.78 \%$ \\
\hline Maret & 734 & 0.003962 & 0 & $0.00 \%$ \\
\hline April & 708 & 0.003886 & 0 & $0.00 \%$ \\
\hline Mel & 728 & 0.00415 & 800 & $0.46 \%$ \\
\hline Juni & 703 & 0.003875 & 1200 & $0.66 \%$ \\
\hline Jull & 732 & 0.00375 & 0 & $0.00 \%$ \\
\hline Agustus & 733 & 0.004262 & 400 & $0.23 \%$ \\
\hline September & 708 & 0.003738 & 0 & $0.00 \%$ \\
\hline Oktober & 728 & 0.003674 & 800 & $0.40 \%$ \\
\hline November & 709 & 0.003774 & 1600 & $0.85 \%$ \\
\hline Desember & 728 & 0.003624 & 800 & $0.40 \%$ \\
\hline
\end{tabular}

*hasil pengolahan data

Presentase Kumulaitf Six Big Loss

\begin{tabular}{|c|c|}
\hline Six Big Losses & Persentase Kumulatif \\
\hline Equipment Failure & $2.39 \%$ \\
\hline Setup Loss & $22.63 \%$ \\
\hline Idling and Minor Stoppage & $15.28 \%$ \\
\hline Reduced Speed Loss & $22.15 \%$ \\
\hline Yield Loss & $4.12 \%$ \\
\hline Rework Loss & $2.67 \%$ \\
\hline
\end{tabular}

*hasil pengolahan data

Dari hasil perhitungan secara kumulatif dalam tahun 2016 seperti ditunjukkan dari tabel diatas, dapat ditarik kesimpulan bahwa losses terbesar adalah berasal dari Setup Loss $22.63 \%$, reduced speed loss $22.15 \%$ dan idling and minor stoppages sebesar $15.28 \%$. 


\section{Diagram Sebab Akibat}

A. Diagram sebab akibat Setup Loss

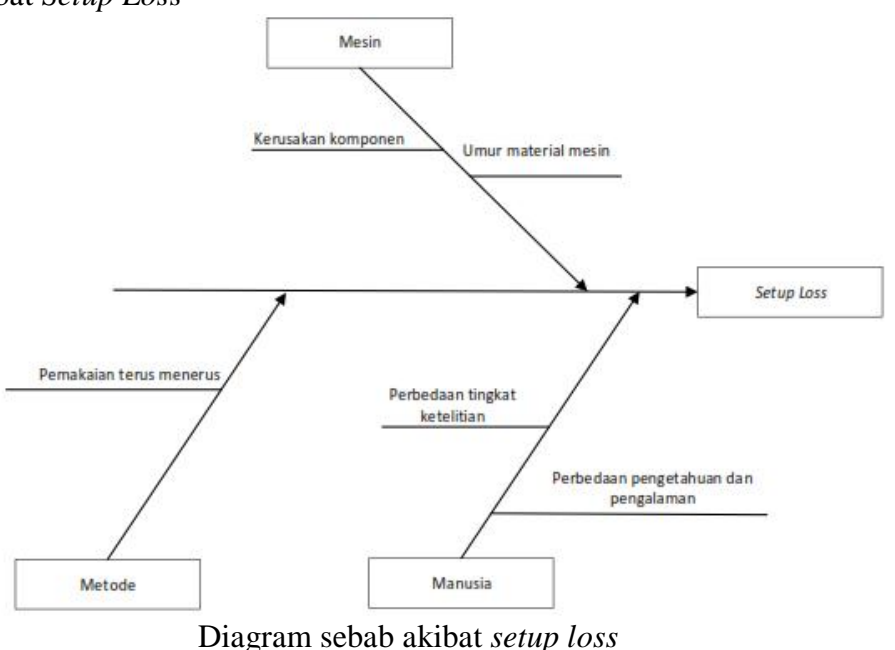

B. Diagram sebab akibat Idling and minor stoppages

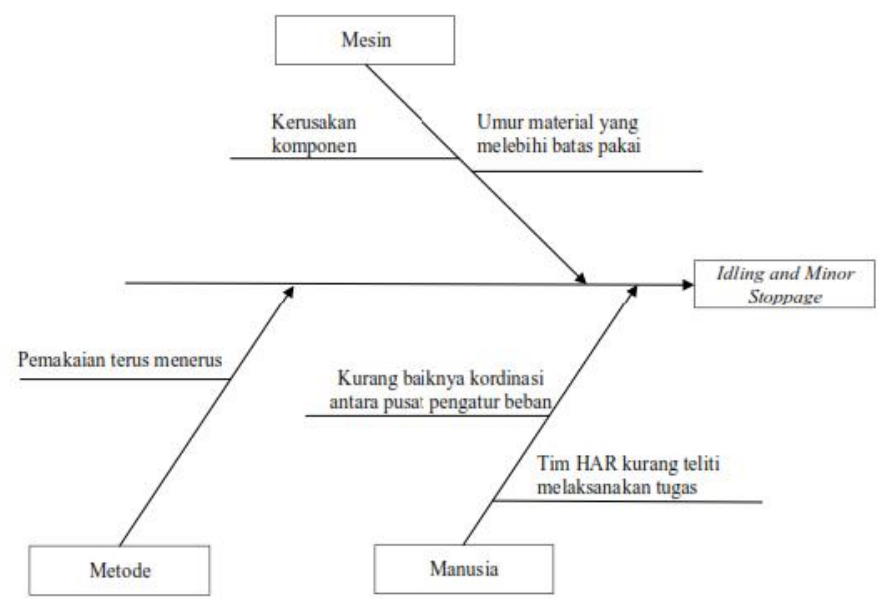

Diagram sebab akibat Idling and minor stoppages

C. Diagram sebab akibat Reduced speed loss

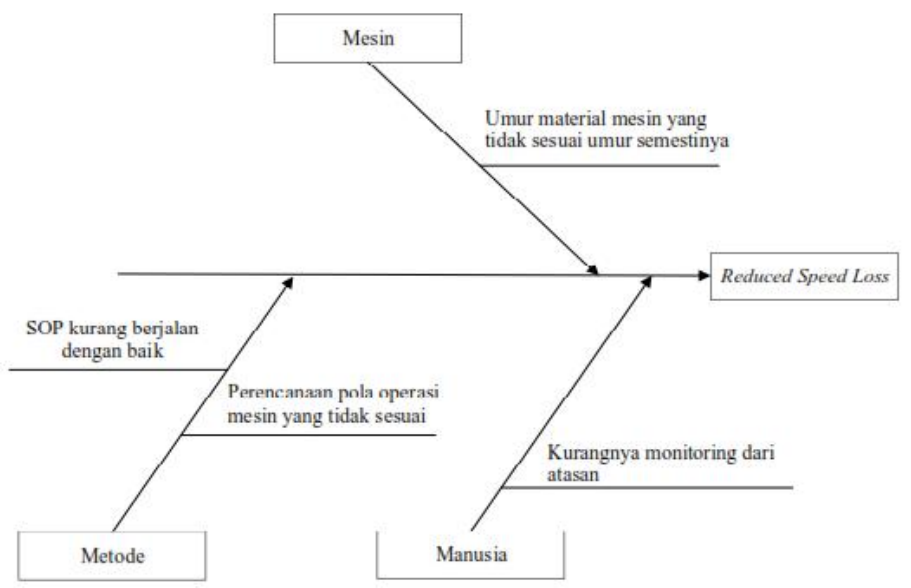

Diagram sebab akibat Reduced speed loss 
Usulan Penyelesaian Masalah

\begin{tabular}{|c|c|c|}
\hline No & Faktor & Penyelesaian Masalah \\
\hline 1 & $\begin{array}{l}\text { Manusia } \\
\text { - Kurangnya monitoring atasan } \\
\text { - Perbedaan tingkat pengetahuan dan } \\
\text { pengalaman }\end{array}$ & 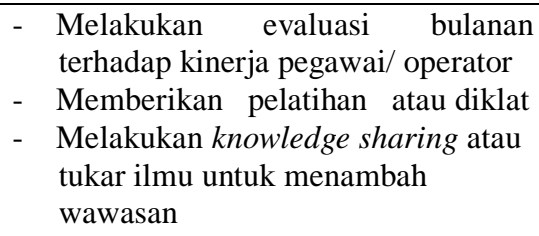 \\
\hline 2 & $\begin{array}{l}\text { Mesin } \\
\text { - Umur material yang sudah } \\
\text { melewati batas pakai/tua } \\
\text { - Perencanaan pola operasi mesin yang } \\
\text { tidak sesuai }\end{array}$ & $\begin{array}{l}\text { - } \text { Melakukan penggantian pada } \\
\text { material yang sudah melewati batas } \\
\text { pakai dengan material baru } \\
\text { - Membuat pola operasi mesin yang } \\
\text { sesuai dengan kebutuhan sistem } \\
\text { sehingga dapat dilakukan } \\
\text { perencanaan yang baik agar mesin } \\
\text { dapat dilakukan secara tepat waktu } \\
\text { dan dapat beristirahat agar } \\
\text { komponen mesin lebih tahan lama. }\end{array}$ \\
\hline 3 & $\begin{array}{l}\text { Metode } \\
\text { - SOP tidak berjalan dengan baik } \\
\text { - Perencanaan jadwal pemeliharaan mesin } \\
\text { yang tidak sesuai }\end{array}$ & $\begin{array}{l}\text { - Melakukan evaluasi SOP dan } \\
\text { melakukan penyesuaikan terhadap } \\
\text { kondisi di lapangan supaya SOP } \\
\text { dapat berjalan dengan baik } \\
\text { - Pelaksanaan pemeliharaan } \\
\text { mesin mengacu pada alat } \\
\text { reminder pemeliharaan }\end{array}$ \\
\hline
\end{tabular}

\section{KESIMPULAN}

Berdasarkan hasil analisa dan uraian hasil pengukuran OEE di PLTD Haruku, dapat diambil beberapa kesimpulan yaitu:

1. Secara umum proses pemeliharaan mesin dengan menggunakan alat reminder pemeliharaan telah memenuhi standar OEE yaitu sebesar $94.37 \%$. Hal ini menunjukkan bahwa penggunaan alat reminder pemeliharaan sangat efektif dalam membantu penerapan TPM yang ideal.

2. Meskipun memiliki nilai OEE yang baik, namun masih terdapat persentase yang cukup tinggi pada perhitungan Six Big Lossess yaitu Setup Losses 22,63 \% , Idling and Minor Stoopage 15.28 \% , dan reduced speed losses $22.15 \%$. Diharapkan dengan adanya evaluasi penyelesaian masalah dengan metode fishbone pada penelitian ini, mampu mengurangi beberapa losses tersebut.

\section{DAFTAR PUSTAKA}

Arikunto, Suharsimi., (2000)., Manajemen Penelitian. Jakarta: PT. Rineka Cipta.

Assauri, Sofjan., (2004)., Manajemen Produksi dan Operasi. Edisi Revisi. Jakarta: Lembaga Penerbit Fakultas Ekonomi Universitas Indonesia.

Corder, Anthony., (1992)., Teknik Manajemen Pemeliharaan terjemahan K. Hadi. Jakarta: Erlangga.

Garpersz, Vincent. (1998). Manajemen Produktivitas Total. Jakarta: Gramedia Pustaka Utama.

Kurniawan, Apprilian., (2017)., Evaluasi Efektivitas Pemeliharaan Menggunakan Alat Bantu Pengecekan Pelumas Dengan Penerapan Total Productive Maintenance (TPM) di PLTD Hative Kecil. Ambon: Fakultas Teknik Universitas Pattimura.

Pusdiklat., (2011)., Diktat Pemeliharaan PLTD. Jakarta: PT PLN (Persero).

Setiawan, F.D., (2008)., Perawatan Mekanikal Mesin Produksi. Yogyakarta: Maximus.

Shirose, Kunio., (1995)., Total Productive Maintenance Team Guide. Portland Oregon: Productivity Press.

Takashi, Yoshikazu, Osada., (2000)., Total Productive Maintenance-TPM, Technical Report. Sweeden: Lulea Tekniska Universitet.

Tajiri, Masaji., (1993)., TPM Implementation, A Japanese Approach. New York. Wireman,

Terry. (2004). Total Productive Maintenance. 2nd ed. New York. 
